\title{
Person Organization Fit, Organizational Commitment and Knowledge Sharing Attitude-An Analytical Study
}

\author{
*Wajid A. Saleem¹, Ghazanfar Adnan¹, Munazza Ambreen² \\ ${ }^{1}$ Iqra University Islamabad, Pakistan \\ ${ }^{2}$ Allama Iqbal Open University Islamabad, Pakistan \\ *wali@hec.gov.pk
}

\begin{abstract}
The purpose of this study is to analyze the relationship among Person Organization Fit (POF), Organizational Commitment (OC) and Knowledge Sharing Attitude (KSA). The paper develops a conceptual frame based on a theory and literature review. A quantitative approach has been used to measure the level of POF and OC as well as to explore the relationship of these variables with KSA \& with each other by using a sample of 315 academic managers of public sector institutions of higher education. POF has a positive relationship with OC and KSA. A positive relationship also exists between OC and KSA. It would be an effective contribution in the existing body of knowledge. Managers and other stakeholders may be helped to recognize the significance of POF, OC and KSA as well as their relationship with each other for ensuring selection of employee's best fitted in the organization and for creating and maintaining a conducive environment for improving organizational commitment and knowledge sharing of the employees which will ultimately result in enhanced efficacy and effectiveness of the organization.
\end{abstract}

Keywords: Person organization fit, Organizational commitment, Knowledge sharing attitude, Public sector higher education institutions of Pakistan.

\section{Introduction}

The success and effectiveness of an organization depends upon many factors. There is no exaggeration to say that the destiny of an organization lies in the hands of the individuals working in it. For a company's competitive advantage, it is inevitable to have talented and loyal individuals (Dawley, Andrews, Bucklew, 2010). Employees work related attitude is of prime importance and management scientists and the researchers are focusing more attention on it. At the same time, the factors that shape these attitudes are also very important. In this context, Person - Organization Fit is the phenomenon having considerable impact upon individual's performance and ultimately organization's success. Similarly, the fit between the individual and the organization has been related to various attitudinal and behavioral outcomes such as job satisfaction, organizational commitment, intention to quit, turnover, and task performance (Wheeler, Gallagher, Brouer, \& Sablynski, 2007; Hoffman \& Woehr, 2006; Brown, Zimmerman \& Johnson, 2005; Verquer, Beehr,\& Wagner, 2003). Sufficient empirical support is there for the notion that Person Organization Fit is an important predictor of positive work-related attitudes (Brown et al., 2005). Person - Organization Fit is generally defined as the compatibility between individuals and the organizations where they work (Sekiguchi, 2003). Speaking more specifically, Person - Organization Fit refers to the states of resemblance between the individual's value and the perceived organizational values. Though empirical research demonstrated that Person - Organization Fit has a strong bearing on organizational outcomes, and it has been proved to be strong determinants for persons' attraction to, selection by and retention in the organizations (Vianen, 2000, Billsberry, Ambrosini, Jones and Marsh, 2005). In Pakistani context, it is still an elusive phenomenon lacking in research.

Along with this, organizational commitment is also linked with organizational performance. Organizational commitment which refers to employees' acceptance, involvement and dedication toward achieving organization's goals and keeping membership with the organization, is a vital factor behind the success of any organization as it increases retention rate, reduces operating cost for recruitment and makes employees committed, hard working and punctual (Jain, Giga, Cooper, 2009; Salami, 2008). In addition to these valuable variables related to organizational performance, knowledge sharing behavior of the employees is also a crucial process for an organization to meet the challenges, to gain competitive advantage and to achieve its targets in an efficient and effective way (Muthosamy, 2009). Knowledge being an important resource must be shared properly between individuals and departments for empowerment of individuals on the one hand and for the betterment of their relations on the other. When people have knowledge sharing attitude, an environment of coordination and cooperation is established; 
individuals become more satisfied and motivated and their collaborated efforts make the organization a symbol of success. Sharing of knowledge contributes to organizational innovation and facilitates competitive advantage (Anand et al, 2007). Despite the demonstrated significance and influential nature of these variables there are significant gaps in the available research and particularly the impact of these variables upon each other is a neglected phenomenon lacking in sufficient imperial support in Pakistani context, particularly. The present study therefore aims to investigate the relationship among Person Organization Fit, Organizational Commitment and the Knowledge Sharing Attitude.

The present study is significant in many ways. Theoretically, it will contribute and add to the existing body of knowledge in the field of Human Resource Management. It will help the managers and other stakeholders to recognize the significance of person organization fit, organizational commitment and knowledge sharing attitude as well as their relationship with each other so that they may focus upon ensuring selection of employees best fitted in the organization and they may be in better position for creating and maintaining a conducive environment for improving organizational commitment and knowledge sharing of the employees which will ultimately lead towards enhanced effectiveness and efficiency of the organization. This study will also open new vendors for the researchers, interested in organizational research to explore these variables from different perspectives.

\section{Review of Literature}

Person - Organization Fit and Organizational Commitment: The concept of POF is not new in management's field. The roots can be traced back in 1950s in the work of organizational behavior scientists (Muthusamy, 2009). With the passage of time and a shift in the focus of human resource management towards ensuring an enjoyable working conditions for employees to reduce turnover and enhance performance level, many variables including person organization fit received theoretical and empirical attention (Chernyshenko, Stark and Williams, 2009). Many researchers concluded that POF is a highly influential variable in an organization and has remarkable positive relationship with the variables like organizational identification (Cable and De Rue, 2002), work behavior (Yaniv \& Farkas, 2005), turn over, job satisfaction etc, indirectly leading towards higher level of commitment to the organization and its goals. Sekiguchi (2003) argued on the basis of his study's findings that similarity between the individual and organizational values influences both the job choice behavior of the applicants and the hiring decisions of the organization. A higher person organization fit results in higher identification of the employees with the objectives of the organization, leading to the more dedication, satisfaction and extra efforts of the employees for the cause of organizational success.

Yaniv and Farkas (2005) explored a unique aspect of POF and concluded that POF has a significant positive affect upon the employee's perception of brand values as to the values declared by the management; this ultimately affects the customers' perception of brand values in a positive way. Coldwell, Billberry, Meurs and Marsh (2008), supported the study by Yaniv \& Faraks (2005) and identified that perception of individuals about corporate reputation (before joining) and actual corporate ethical values affect individual's sense of fit and their retention behavior. Their proposed model suggest that if there is a misfit between the organization's expected ethical values and the actual prevailing ethical values the result would be problematic acquisition and retention. Intention to leave the organization or low retention is the consequences of low level of organizational commitment. Some researchers also explored the association between POF and organizational commitment and found a positive relationship between these two variables (Muthusamy, 2009; Guan et al. 2011; Brown et al. 2005). As such, literature tells that Person - Organization Fit is a highly influential variable, generating numerous positive outcomes for an organization. However, relationship of POF with organizational commitment which itself is a strong determinant of organization performance is not exclusively studied and is required to be explored further. Therefore, the presently study is designed to find out the relationship between POF and OC.

H1: There is a positive relationship between person organization fit and organizational commitment

Organizational Commitment and Knowledge Sharing Attitude: Organizational commitment, a complex phenomenon that can be defined in many ways with little consensus. Shore, Barksdale and Shore (1995) based on their study findings argued that the manager rated affective commitment has a positive relationship and continuance commitment has a negative relationship with the potential and promotability of employees. The study indicated that the managers treated the employees on the basis of the judgment regarding the type \& level of their commitment to the organization. Organizational 
commitment is affected by organizational culture as well as subcultures. Lok \& Crawford (1999) found a stronger association of organizational commitment with subcultures of the organization as compared to organizational culture. Along with culture leadership behavior also determine the level of organizational commitment. Yousef (1998) argued that employees of a consultative or participative leader have higher level of organizational commitment as a result their performance level is also high. Chen, Silverthorne \& Hung (2006) explored another determinant of organizational commitment that is organization communication. In this context, they studied the accounting professionals in Taiwan and America. They found a higher level of organizational commitment in American as compared to Taiwani accounting professionals. Salami (2008) found in his study that demographic variables except gender and all the other factors were found to be significant predictor of organizational commitment. It was suggested that during program design for organizations all these factors should be considered. A moderate positive correlation was indicated between organizational commitment and job involvement in a study conducted by Uygur \& Kilic (2009). The respondents were selected from central organizations of ministry of health in Turkey. Khan, Ziauddin, Jam and Ramay (2010) investigated the impact of organizational commitment on job performance and a positive relationship was found between these two variables and normative commitment was found to have more significant impact upon performance as compared to other two components of commitment.

A very important, interesting \& comprehensive study by Han, Chiang and Chang (2010) found a positive association between employees' participation in decision making and psychological ownership. Psychological ownership has a positive relationship with organization commitment and organizational commitment and knowledge sharing are also positive correlated. Muthusamy (2009) identified that persons with the high level of affective commitment to their organizations were more willing to share tacit knowledge with their colleagues. In 2010, Han et al investigated the relationship between two variables and found it to be positive and significant.

H2: There is a positive relationship between organizational commitment and knowledge sharing attitude.

Person - Organization Fit and Knowledge Sharing Attitude: Knowledge sharing attitude of the employees is an inevitable prerequisite to create and utilize knowledge without which the effectiveness of the organization is out of question. Anand et al (2007) cited in Han et al (2010) argues that for the success of the organization, it must be ensured that persons share tacit knowledge with each other. Dyer \& Nobeoka (2000) discussed different dilemmas regarding knowledge sharing attitude. First of them is the motivation of the employees to share tacit knowledge. Second is the free rider problem referring to achieve collaboration among self interested individuals and the third dilemma is related to maximizing the efficiency of knowledge transfer. They based on their study argued that Toyota's network has solved all the dilemmas successfully and as a result enjoying productivity advantages. Han et al (2010) argued on the basis of previous research studies that employees with sense of psychological ownership usually have altruistic spirit which is an important antecedent of knowledge sharing attitude and psychological ownership is a result of POF. Muthusamy (2009) proved that POF correlate positively with knowledge sharing factors. Therefore it is hypotheses:

H3: A positive relationship exists between person organization fit and knowledge sharing attitude.

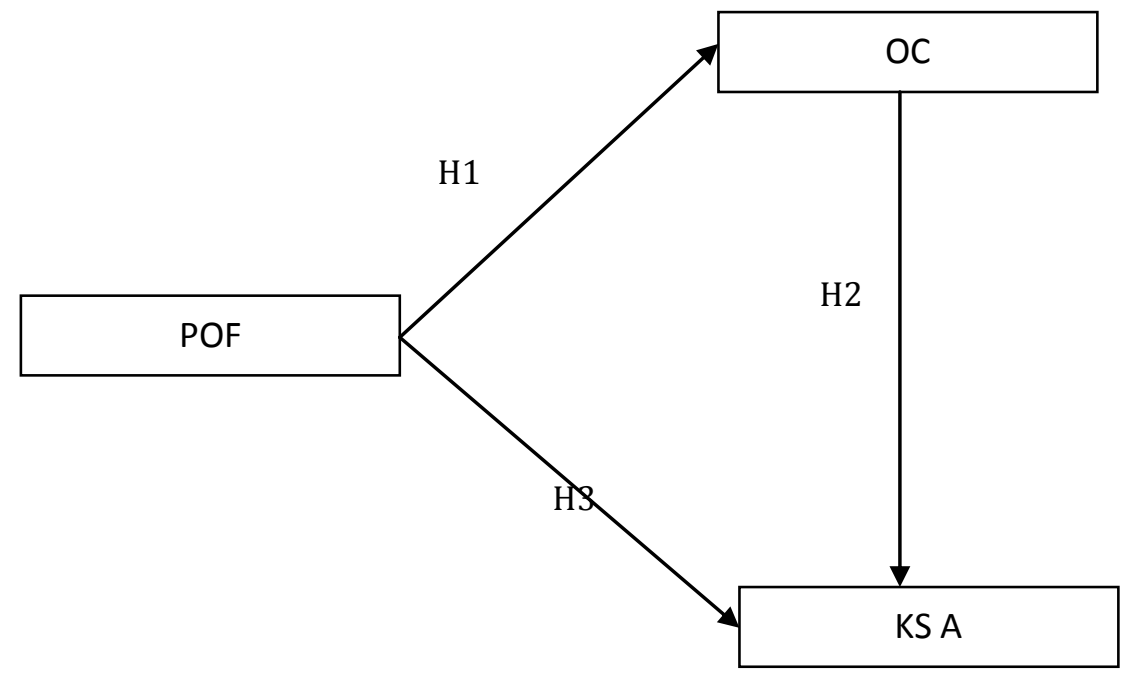




\section{Research Method}

The present study was descriptive in nature. Quantitative approach and survey research design used.

Population and Sample: The study was conducted in service industry and public sector higher education institutions (Universities) located in Rawalpindi and Islamabad were taken as firms. Total no of the universities is 11 . The population of the study comprised of the academic staff of these universities and total population size was 3034. Fifteen (15) percent of the population was taken as the sample. Simple random sampling technique was used to select the representative sample of the population. The actual sample size was 455 whereas 317 completed surveys were received (i.e. a response rate of $70 \%$ ).

Instruments: Three research instruments were used to collect data from sample. Bretz and Judge's Person-Organization Fit inventory (1992) was adopted to measure Person-Organization Fit in this study. Fit was assessed using two 15-item scales regarding Organization Characteristics and Individual preference. Fit was operationalized as the sum of the differences between responses to corresponding items on the two scales using a 5-point Likert-type scale; 1 = strongly disagreed to 5 strongly agreed. Organizational commitment inventory by Mayer \& Allen (1997) was used as another research instrument, comprised of 19 items constructed on 7 point scale. Whereas, a three-item scale, based on Bartol and Srivastava (2002) and Becerra-Fernandez and Sabherwal (2001), was used to measure individual knowledge sharing behavior. Scoring criterion of the items was in a way that higher scores indicated higher level of POF, OC and KSA. Data were collected through personal visit of the researcher to the sample organizations and in face to face meetings with the respondents. Responses were analyzed statistically through SPSS by using correlation and regression.

\section{Results and Discussion}

The results of the study are explained below.

\section{Correlation Test}

Table 1: Correlation Matrix of Relationship between Organization Commitment (Affective, Normative, Continuous), Person - Organization Fit and Knowledge Sharing Attitude

\begin{tabular}{|c|c|c|c|c|c|c|c|}
\hline $\mathbf{S} / \mathbf{N}$ & Item & $\mathbf{1}$ & 2 & 3 & 4 & 5 & 6 \\
\hline 1 & Affective Organizational Commitment & 1.000 & & & & & \\
\hline 2 & Normative Organizational Commitment & $.950^{* *}$ & 1.000 & & & & \\
\hline 3 & Continuous Organizational Commitment & $.853^{* *}$ & $.830^{* *}$ & 1.000 & & & \\
\hline 4 & Organization Commitment & $.974^{* *}$ & $.966^{* *}$ & $.935^{* *}$ & 1.000 & & \\
\hline 5 & Person - Organization Fit & $.696^{* *}$ & $.696^{* *}$ & $.686^{* *}$ & $.723^{* *}$ & 1.000 & \\
\hline 6 & Knowledge Sharing Attitude & $.599^{* *}$ & $.638^{* *}$ & $.624^{* *}$ & $.648^{* *}$ & $.627^{* *}$ & 1.000 \\
\hline
\end{tabular}

**Correlation is significant at the 0.01 level (2-tailed).

The statistical analysis given at table 1 above supports all the hypotheses. Person Organization Fit has a significant positive relationship with Organizational Commitment. $(r=.723, \mathrm{p}<.01)$. The coefficient correlation $(\mathrm{r}=.723)$ indicates high positive correlation between these two variable. Similarly, Organizational Commitment has a positive relationship with Knowledge Sharing Attitude. $(r=.648$, $\mathrm{p}<.01)$. The coefficient correlation ( $\mathrm{r}=.648)$ indicates a moderate positive correlation between these two variables. Moreover, the table 1 also highlights that a positive correlation exists between Person Organization Fit and Knowledge Sharing attitude. $(r=.627, p<.01)$. The coefficient correlation $(r=.627)$ indicates a moderate positive correlation between these two variables. This positive correlation is a bit lower than the correlation found between Organizational Commitment and Knowledge Sharing Attitude but it is remarkably lower than the relationship between Person Organization Fit and Organizational Commitment.

\section{Regression Analysis}

Table 2: Person - Organization Fit as a predictor of Organizational Commitment

\begin{tabular}{llllllllllll}
\hline \multicolumn{1}{c}{$\mathbf{R}$} & \multicolumn{1}{c}{ R Square } & \multicolumn{1}{c}{ F } \\
\hline AOC & NOC & COC & OC & AOC & NOC & COC & OC & AOC & NOC & COC & OC \\
$.696^{*}$ & $.696^{*}$ & $.686^{*}$ & $.723^{*}$ & .485 & .485 & .471 & .523 & 296.100 & 296.555 & 279.966 & 345.105
\end{tabular}

\footnotetext{
$*=$ significant at level of 0.01
} 
Dependent Variable: Organizational Commitment (OC) [Affective Organizational Commitment (AOC), Normative Organizational Commitment (NOC) and Continuous Organizational Commitment (COC)]

Table 3: Organizational Commitment viz. Affective Organizational Commitment (AOC), Normative Organizational Commitment (NOC) and Continuous Organizational Commitment as predictors of Knowledge Sharing Attitude

\begin{tabular}{llllllllllll}
\hline \multicolumn{1}{c}{ R } & \multicolumn{1}{c}{ R Square } & \multicolumn{4}{c}{$\mathbf{F}$} \\
\hline AOC & NOC & COC & OC & AOC & NOC & COC & OC & AOC & NOC & COC & OC \\
$.599^{*}$ & $.638^{*}$ & $.624^{*}$ & $.648^{*}$ & .359 & .407 & .390 & .420 & 176.378 & 216.054 & 200.898 & 227.668
\end{tabular}

Dependent Variable: Knowledge Sharing Attitude (KSA)

Table 4: Person - Organization Fit as predictor of Knowledge Sharing Attitude

\begin{tabular}{lrrrr}
\hline Model & R & R Square & F & Sig. \\
\hline 1 & $.627^{\mathrm{a}}$ & .393 & 203.588 & $.000^{\mathrm{a}}$ \\
\hline
\end{tabular}

Dependent Variable: Knowledge Sharing Attitude (KSA)

The regression analysis indicates that independent variable Person Organization Fit is significant predictor of organizational commitment and knowledge sharing attitude. Independent variable Organizational Commitment viz. Affective Organizational Commitment (AOC), Normative Organizational Commitment (NOC) and Continuous Organizational Commitment as Independent variable is also a significant predictor of Knowledge Sharing Attitude.

The findings of the study indicated that Person - Organization Fit \& Organizational Commitment have positive relationship with each other. Person - Organization Fit is a strong predictor of Organizational Commitment and as Organizational Commitment is a highly influential variable leading towards numerous positive outcomes for the organization (Khan et al. 2010 and Han et al., 2010). It is therefore necessary that higher education institutions of Pakistan should attract and retain academic managers whose personal values are best matched with organizational values, this high level of person organization fit will be helpful for creating and maintaining conducive environment for improving organizational commitment which will ultimately lead towards enhanced effectiveness of these organizations. Consequently the major HRM issues for example turn over and absenteeism can be addressed. Data analysis reveals that employees with high level of Person - Organization Fit are more likely to share knowledge with their colleagues. As sharing of knowledge is a prerequisite for organizational effectiveness (Anand et al, 2007 cited in Han et al., 2010) organizations should facilitate knowledge sharing through provision of appropriate communication channels and motivation of employees and above all if there is person organization fit, sharing of knowledge would be maximum. The results of the study are consistent with the previous studies that found a positive correlation between person organization Fit and knowledge sharing behavior of the employees (Muthusamy, 2009).

The results of the study also reinforce the notion that employees with high level of organizational commitment exhibit more willingness to share new idea, information and knowledge. Sharing of knowledge is followed by innovation and high organization performance (Anand et al, 2007). Managers should focus upon the policies and practices that foster commitment of the employees with the organization. The managers should design the performance appraisal system which, along with other factors, covers organizational commitment level and knowledge sharing attitude of the employees as committed employees with positive knowledge sharing attitude are the real asset to any organization.

\section{Conclusion}

The present study analyzed the relationship among Person Organization Fit, Organizational Commitment and Knowledge Sharing Attitude. The analyzed data revealed a positive relationship between Person Organization Fit and Organizational Commitment. This relationship was found to be significant as well. It was revealed that Person Organization Fit is a strong predictor of Organizational Commitment. A positive relationship was also found between Person Organization Fit and Knowledge Sharing Attitude and it was also indicated that Person organization Fit is a strong predictor of Knowledge Sharing Attitude. Organizational Commitment and Knowledge Sharing Attitude were also found to be positively correlated in this study and it was identified that persons with high level of Organizational Commitment are more 
likely to share knowledge at workplace. In conclusion, organizations should adopt the policies and practices that ensure recruitment and retention of the employees with high level of Person Organization Fit so that Organizational commitment can be ensured and Knowledge Sharing Attitude can be fostered and consequently, organizational performance can be maximized.

Limitations and Future Research: It seems necessary here to discuss some limitations of present study. Firstly, the data for the present study was collected through a single source for each variable. In order to control this limitation future research should collect data from more than one means to make the findings more authentic and reliable. Secondly, the study was limited to single sector. Other service sectors such as hospitals, banks etc. should be focused by future researchers so that some common model for service sector regarding Person Organization Fit, Organizational Commitment and Knowledge Sharing Attitude can be proposed or otherwise. Finally, the present study did not take into account the antecedents of all three variables. Future research can also be conducted to find out the contributing factors of these variables.

\section{References}

Anand, N., Gardner, H. K, \& Morris, T. (2007). Knowledge-based Innovation: Emergence and Embedding of New Practice Areas in Management Consulting Firms. Academy of Management Journal, 50, 406428.

Bartol, K. M. \& Srivastava, A. (2002). Encouraging Knowledge Sharing: The Role of Organizational Reward Systems. Journal of Leadership and Organization Studies, 9, 64-76.

Becerra-Fernandez, I. \& Sabherwal, R. (2001).Organizational Knowledge Management: A Contingency Perspective. Journal of Management Information Systems, 18, 23-55.

Billsberry, J., Ambrosini, P. J. G., Marsh, J., Moss, J. \& Meurs, N. (2005). Towards a Composite Map of Organizational Person-Environment Fit, Paper presented at the British Academy of Management.

Brown, A. L., Zimmerman, R. D. \& Johnson, E. C. (2005). Consequences of individuals' fit at work: A metaanalysis of person-job, person-organization, person-group, and person-supervisor fit. Personnel Psychology, 58, 281-342.

Cable, D. M. \& DeRue, D. S. (2002). The convergent and discriminant validity of subjective fit perceptions: Journal of Applied Psychology 87, 875-884.

Chen, J., Silverthorne, C. \& Hung, Y. (2006).Organization communication, job stress, organizational commitment, and job performance of accounting professionals in Taiwan and America: Leadership \& Organization Development Journal, 27(4), 242-249.

Chernyshenko, O. S., Stark, S. \& Williams, A. (2009). Latent Trait Theory Approach to Measuring PersonOrganization Fit: Conceptual Rationale and Empirical Evaluation. International Journal of Testing, 9(4), 358-380.

Coldwell, D., Billberry, J., Van Meurs, N. \& Marsh, P. (2008). The effect of person organization fit on employee attraction and retention; towards a testable, explanatory model; workforce and retention study. Planning Institute of Australia (SA Division), 87-117.

David. D. D., Andrews M. C. \& Bucklew, N. S. (2010). Enhancing the ties that bind: mentoring as a moderator. Career Development International, 15(3), 259-278.

Dyer, J. H. \& Nobeoka, K. (2000). Creating and managing a high-performance knowledge-sharing network: the Toyota case. Strategic Management Journal, 21, 345-67.

Guan, Y., Deng, H., Bond, H. M., Zhang, Z. \& Hu, T. (2011).The Interplay between Social Cynicism Beliefs and Person-Organization Fit on Work-Related Attitudes among Chinese Employees: Journal of Applied Social Psychology, 41(1), 160-178.

Han, T. Chiang, H. \& Chang, A. (2010).Employee participation in decision-making, psychological ownership and knowledge sharing; mediating role of organizational commitment in Taiwanses high tech organizations: The International journal of Human Resource Management, 21(12), 2218-2233.

Hoffman, B. J. \& Woehr, D. J. (2006). A quantitative review of the relationship between personorganization fit and behavioral outcomes. Journal of Vocational Behavior, 68, 389-399.

Jain, A. K., Giga, S. I., \& Cooper, C. L. (2009). Employee wellbeing, control and organizational commitment. Leadership and Organization Development Journal, 30(3), 256-273.

Khan, R. M., Ziauddin, M., Jam, F. A. \& Ramay, M. I. (2010). The Impacts of Organizational Commitment on Employee Job Performance. European Journal of Social Sciences, 15(3), 292-298. 
Lok, P. \& Crawford, J. (1999). The relationship between commitment and organizational culture, subculture, leadership style and job satisfaction in organizational change and development. Leadership \& Organization Development Journal, 20(7), 365-373.

Meyer, J. P. \& Allen, N. J. (1997). Commitment in the Workplace: Theory, Research, and Application. Thousand Oaks, CA: Sage Publications.

Muthusamy, V. (2009). Affective Commitment, Person-Organization Fit and Turnover Intention: Examining the effect of knowledge sharing. California Management Review, 76, 2230-2247.

Salami, O. S. (2008). Demographic and Psychological Factors Predicting: Organizational Commitment among Industrial Workers Anthropologist, 10(1), 31-38.

Sekiguchi, T. (2003). A contingency perspective on the importance of P-J fit and P-O fit in employee selection. Paper presented at the Annual Conference of Academy of Management, Seattle, WA.

Shore, L. M. Barksdale, K. \& Shore, H. T. (1995). Managerial Perceptions of Employee Commitment to Organization. Academy of Management Journal, 38, 1593-1615

Uygur, A. \& Kilic, G. (2009). A Study into Organizational Commitment and Job Involvement: An Application towards the Personnel in the Central Organization for Ministry of Health in Turkey. Ozean Journal of Applied Sciences, 2(1), 113-125.

Van Vianen, A. E. M. (2000). Person-organization fit: The match between newcomers' and recruiters' preferences for organizational cultures. Personnel Psychology, 53, 113-149.

Verquer, M. L., Beehr, T. A., \& Wagner, S. H. (2003). A meta-analysis of relations between personorganization fit and work attitudes: Journal of Vocational Behavior, 63, 473- 489.

Wheeler, A. R., Gallagher, V. C. Brouer, R. L. \& Sablynski, C. J. (2007). When person-organization (mis)fit and (dis)satisfaction lead to turnover: The moderating role of perceived job mobility. Journal of Managerial Psychology, 22(2), 203-219.

Yaniv, E. \& Farkas, F. (2005). The Impact of Person-Organization Fit on the Corporate Brand Perception of Employees and of Customers: Journal of Change Management, 5(4), 447-461.

Yousef, A. D. (1998). Satisfaction with job security as a predictor of organizational commitment and job performance in a multicultural environment: International Journal of Manpower, 19(3), 184-194. 